\title{
Food Intake Behavior in Cancer Survivors in Comparison With Healthy General Population; From the Health Examination Center-based Cohort
}

\author{
Tung Hoang ${ }^{1}$, Jeonghee Lee ${ }^{1}$, Jeongseon Kim ${ }^{1}$, Boyoung Park ${ }^{2}$ \\ ${ }^{1}$ National Cancer Center Graduate School of Cancer Science and Policy, Goyang, ${ }^{2}$ Department of Medicine, Hanyang University College of Medicine, \\ Seoul, Korea
}

\begin{abstract}
Background: This study aimed to investigate the food intake behavior of cancer survivors based on main sources of energy intake from different food groups in comparison with healthy individuals.

Methods: Baseline survey data from the Health Examinee cohort, which recruited participants from 2014 to 2013 were applied. A total of 5,269 cancer survivors and 5,219 healthy subjects without comorbidities who were matched by age, sex, and enrollment center were included in the analysis. The proportion of energy intake for 17 food groups was devided into lower median and median or upper. OR and $95 \%$ Cls were determined to measure the difference of energy intake proportion in cancer survivors, five major types of cancer survivors versus healthy individuals.

Results: Generally, the proportion of calories intake from sugars and sweets, meat and poultry, oils and fats, and beverage was lower in cancer survivors than in healthy individuals $(\mathrm{OR}=0.83[95 \% \mathrm{Cl}=0.79-0.88], 0.75[95 \% \mathrm{Cl}=0.71-0.80], 0.84[95 \% \mathrm{Cl}=0.80-0.89]$, and $0.93[95 \% \mathrm{Cl}=0.88-0.99]$, respectively) with more prominently shown in breast, colon, and thyroid cancer individuals. In contrast, cancer survivors tended to intake calories from potatoes and starches, legume, seeds and nuts, vegetables, mushrooms, fruits, and seasonings more than healthy individuals $(O R=1.09[95 \% \mathrm{Cl}=1.03-1.16], 1.13[95 \% \mathrm{Cl}=1.06-1.19], 1.15[95 \% \mathrm{Cl}=1.09-1.22]$, $1.07[95 \% \mathrm{Cl}=1.01-1.13], 1.07[95 \% \mathrm{Cl}=1.02-1.14], 1.15[95 \% \mathrm{Cl}=1.08-1.21]$, and $1.17[95 \% \mathrm{Cl}=1.10-1.23]$, respectively) which were more prominent in gastric and breast cancer survivors.

Conclusions: The dietary behavior measured by main sources of energy intake in cancer survivors was different from healthy individuals in terms of several food groups. Although there are nutrition guidelines for cancer survivors, because of the differences between Western population and Asian people in terms of food culture, the guidelines for balanced nutritious behavior should be established among Asian cancer survivors.
\end{abstract}

(J Cancer Prev 2019;24:208-216)

Key Words: Cancer survivors, Energy intake, Nutrition status

\section{INTRODUCTION}

Over several decades, the number of both cancer incidence and survivors has been increasing rapidly [1,2], with 14.1 million of new cancer cases and 32.6 million of 5-year cancer survivors worldwide [3]. In Korea, the 5-year cancer survival rate has been improved from $41.2 \%$ to $70.3 \%$, followed by rapidly increasing number of cancer survivors and increased long-term cancer related health burden in the society [4,5]. These cancer survivors have higher risk of developing not only secondary cancers but also several chronic diseases such as cardiovascular disease and endocrine disease $[6,7]$.

The association between diet and cancer is one of the important interest because it is one of modifiable risk factors which might be directed toward healthier choices for both cancer incidence and survival [8]. In the aspect of incidence, in the meta-analysis study targeting Korean population, soy foods, fruits, and vegetables were associated with a decreased risk of

Received November 30, 2019, Revised December 18, 2019, Accepted December 20, 2019

Correspondence to: Boyoung Park

E-mail: hayejine@hanmail.net, ORCID: Boyoung Park, https://orcid.org/0000-0003-1902-3184

Copyright (C) 2019 Korean Society of Cancer Prevention

(C) This is an Open Access article distributed under the terms of the Creative Commons Attribution Non-Commercial License (http://creativecommons.org/licenses/by-nc/4.0) which permits unrestricted non-commercial use, distribution, and reproduction in any medium, provided the original work is properly cited. 
cancer but high salt foods or meat intake increased the risk of gastric or colorectal cancer [9]. In general, high-quality diet such as fruit, vegetables, grains, poultry, and low-fat diary products is observed to reduce overall mortality and recurrence among cancer survivors, whereas Western dietary pattern including red and processed meat, refined grains, sweets and desserts, and high-fat dairy products is associated with an increase of overall mortality and recurrence [10]. However, studies of diet and cancer outcome in East Asian countries were limited.

From our previous analysis, we identified that the proportion of total calories intake from carbohydrates was higher and that from fat or protein was lower in cancer survivors compared with healthy population, suggesting imbalanced nutrition intake with extremely limited intake of cancer incidence-related nutrition such as fat in an East Asian population [11]. These results were opposite from the Western population in which cancer survivors had higher intake of saturated fat than recommended level [12]. The nutrition imbalance in cancer survivors would result from their eating behaviors. In cancer survivors from Western population, their eating behaviors were found not to follow diet guidelines with much empty calories and less fiber compared with general population [12]. However, in cancer survivors in East Asian population, despite of imbalanced nutrition which was different from survivors in a Western country [11], their eating habits have not been studied much. Identifying the food intake behaviors in cancer survivors based on details of daily calories from different types of food group would play an important role in evaluating dietary patterns and educating better eating behaviors for cancer survivors who are vulnerable to other chronic diseases affected by food intake [13].

Therefore, we conducted this study to evaluate the food intake behavior in cancer survivors based on main sources of energy intake from different food groups in comparison with healthy individuals. Also, we investigated the food intake behavior by five main types of cancer as well.

\section{MATERIALS AND METHODS}

\section{Study population}

The Korean Genome Epidemiology Study (KoGES) is an ongoing consortium project from 2001, which consists of six prospective cohort studies [14]. The Institutional Review Board of the National Cancer Center approved this study protocol, which was in compliance with the Declaration of Helsinki (IRB No: NCC2014-0098). This study used the baseline survey data from the Health Examinee (HEXA) cohort, which is a part of KoGES, as a cross-sectional approach [14]. In the HEXA cohort study, the participants aged 40 to 69 were recruited from 38 centers [15]. The trained staffs collected information on socio-demographic characteristics, history of disease, medication, and family, lifestyle behaviors of alcohol and tobacco, and diet through structured questionnaire including semi-food frequency questionnaire (semi-FFQ) as well as biological specimens by using a standardized protocol [15]. Participants who reported that they had been diagnosed with any type of cancer from a physician were defined as cancer survivors as the guideline of DeSantis et al. [16], which identified as any person who had been diagnosed with any type of cancer, either who are under treatment or who had completely recovered as cancer survivors. As a result, a total of 5,274 cancer survivors and 168,038 non-cancer individuals were identified. To select healthy population as a reference group, those who reported that they had diagnosed any of chronic

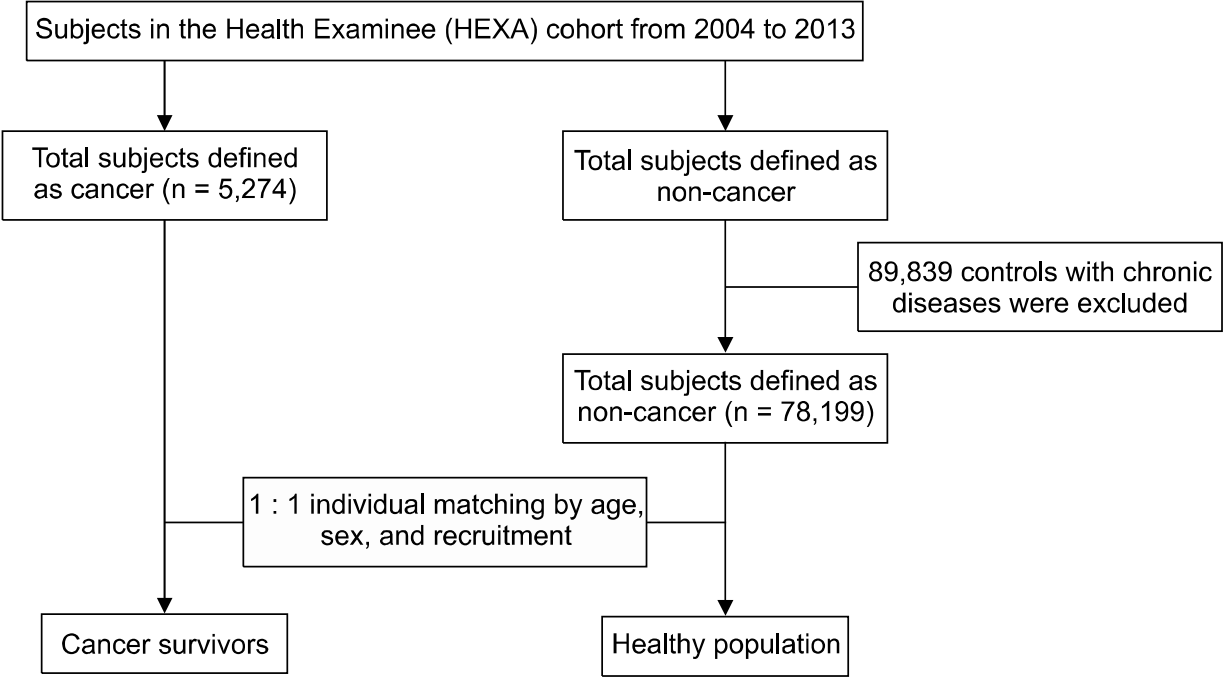

Figure 1. Flow chart of selecting study subjects in the study. 
diseases from a physician were excluded, remaining 78,199 healthy people. After individual matching with $1: 1$ ratio by age ( \pm 2 years), sex (male and female), and enrollment center location
(38 centers) and excluding those with missing values in semi-FFQ, 5,269 cancer survivors and 5,219 healthy subjects were included in the final analysis (Fig. 1).

Table 1. Baseline sociodemographic characteristics of study population

\begin{tabular}{|c|c|c|c|}
\hline Characteristic & Healthy population $(\mathrm{n}=5,219)$ & Cancer $(\mathrm{n}=5,269)$ & $P$-value ${ }^{a}$ \\
\hline Age (yr) & $55.81 \pm 8.15$ & $55.69 \pm 8.07$ & $0.45^{\mathrm{b}}$ \\
\hline$<50$ & $1,266(24.26)$ & $1,267(24.05)$ & 0.96 \\
\hline $50-54$ & $1,109(21.25)$ & $1,109(21.05)$ & \\
\hline $55-59$ & $1,019(19.53)$ & $1,023(19.42)$ & \\
\hline $60-64$ & $966(18.51)$ & $972(18.45)$ & \\
\hline$\geq 65$ & $859(16.46)$ & $898(17.04)$ & \\
\hline \multicolumn{4}{|l|}{ Sex } \\
\hline Male & 1,304 (24.99) & $1,320(25.05)$ & 0.96 \\
\hline Female & $3.915(75.01)$ & $3.949(74.95)$ & \\
\hline \multicolumn{4}{|l|}{ Marital status } \\
\hline Married, cohabitant & $4,533(86.86)$ & $4,566(86.66)$ & 0.06 \\
\hline Others & $602(11.53)$ & $680(12.91)$ & \\
\hline Missing & $84(1.61)$ & $23(0.44)$ & \\
\hline \multicolumn{4}{|l|}{ Education } \\
\hline$<$ High school & $2,015(38.60)$ & $1,973(37.45)$ & 0.16 \\
\hline High school graduate & 1,795 (34.39) & $1,883(35.74)$ & \\
\hline$\geq$ College & $1,267(24.28)$ & $1,352(25.66)$ & \\
\hline Missing & $142(2.72)$ & $61(1.16)$ & \\
\hline \multicolumn{4}{|c|}{ Monthly household income ${ }^{c}$} \\
\hline$<\$ 1,860$ & $1,815(34.78)$ & $1,789(33.95)$ & 0.05 \\
\hline$\$ 1,860-3,720$ & $1,623(31.10)$ & $1,798 \quad(34.12)$ & \\
\hline$\geq \$ 3.720$ & $921(17.65)$ & $954(18.11)$ & \\
\hline Missing & $860(16.48)$ & $728(13.82)$ & \\
\hline \multicolumn{4}{|l|}{ Employment status } \\
\hline Employed & $2,340(44.84)$ & $2,005(38.05)$ & $<0.001$ \\
\hline Unemployed & $2,698 \quad(51.70)$ & $3.194(59.76)$ & \\
\hline Missing & $181(3.47)$ & $115(2.18)$ & \\
\hline \multicolumn{4}{|l|}{ Smoking status } \\
\hline Never & $4,142(79.36)$ & $4,143(78.63)$ & $<0.001$ \\
\hline Past & $555(10.63)$ & $819(15.54)$ & \\
\hline Current & $444(8.51)$ & $280(5.31)$ & \\
\hline Missing & $78(1.49)$ & $27(0.51)$ & \\
\hline \multicolumn{4}{|l|}{ Drinking status } \\
\hline Never & $3,019(57.85)$ & $3,275(61.56)$ & $<0.001$ \\
\hline Past & $132(2.53)$ & $527(10.00)$ & \\
\hline Current & $1,990(38.13)$ & $1,444(27.41)$ & \\
\hline Missing & $78(1.49)$ & $23(0.44)$ & \\
\hline \multicolumn{4}{|l|}{ Regular exercise } \\
\hline No & $2,530(48.48)$ & $2,203(41.81)$ & $<0.001$ \\
\hline$<150 \mathrm{~min} / \mathrm{wk}$ & $238(4.56)$ & $281 \quad(5.33)$ & \\
\hline$\geq 150 \mathrm{~min} / \mathrm{wk}$ & $2,205(42.25)$ & $2,645(50.20)$ & \\
\hline Missing & $246(4.71)$ & $140(2.66)$ & \\
\hline \multicolumn{4}{|l|}{ Body mass index } \\
\hline$<23.0 \mathrm{~kg} / \mathrm{m}^{2}$ & $2,245(43.16)$ & $2,280(43.27)$ & 0.09 \\
\hline $23.0-24.9 \mathrm{~kg} / \mathrm{m}^{2}$ & $1,466(28.09)$ & $1,392(26.42)$ & 0.07 \\
\hline$\geq 25.0 \mathrm{~kg} / \mathrm{m}^{2}$ & $1,483(28.42)$ & $1,578(29.95)$ & \\
\hline Missing & $25(0.48)$ & $19(0.36)$ & \\
\hline
\end{tabular}

Values are presented as mean \pm SD or number (\%). ${ }^{a}$ Perform chi-square test to compare the difference between two discrete variables. ${ }^{b}$ Perform $t$-test to compare the mean difference between two groups. 'Income was converted from Korean Won (KRW) to US dollar (USD) with current rate of 2017 (1,075 KRW is approximately 1 USD). 


\section{Food intake behavior}

The food intake behavior was assessed by using a validated semi-FFQ with 106 food items [17]. In the semi-FFQ, the food intake behaviors were measured by average frequency of servings per week and average portion size during the last 1 year. Based on age, Sex, height, weight, type of food intake, frequency of servings, and portion sizes, the 106 food items were converted to the daily energy intake of 663 food combinations and then again converted to 17 food groups using the Computer-Aided Nutritional Analysis Program (CAN-Pro) 4.0 (Korean Nutrition Information Center, Seoul, Korea) [18]. These 17 food groups included cereals and grain, potatoes and starches, sugars and sweets, legume, seeds and nuts, vegetables, mushrooms, fruits, meat and poultry, eggs, fishes and shellfishes, seaweeds, milks and diary, olds and fats, beverage, seasonings, and others. Food intake behavior was determined by calculating the proportion of calories intake of each 17 food groups.

\section{Statistical analysis}

All statistical analyses were performed by using SAS ver. 9.4 (SAS Institute, Cary, NC, USA), and R ver. 3.2.2 (R foundation, Vienna, Austria). To compare baseline characteristics between cancer survivors and healthy population, we performed chi-square test. The mean of proportion of energy intake from each 17 food groups between all cancer survivors and matched healthy population was compared by using $t$-test. Also, we conducted subgroup analysis of food intake behavior for each cancer type with 300 or more cases by using ANOVA with a post hoc comparison (Tukey's test). As the result, gastric cancer ( $\mathrm{n}=$ $731)$, colon cancer $(n=378)$, breast cancer $(n=875)$, cervical cancer ( $\mathrm{n}=609)$, and thyroid cancer $(\mathrm{n}=888)$ survivors in comparisons with healthy population were included in the subgroup analysis.

The proportion of energy intake for 17 food groups were divided into lower median and median or upper in the study population. To compare the diet intake behavior which was

Table 2. The proportion of calories intake among cancer survivors and healthy population

\begin{tabular}{|c|c|c|c|c|c|c|c|}
\hline Food group & $\begin{array}{c}\text { Healthy } \\
\text { population } \\
(\mathrm{n}=5,219)\end{array}$ & $\begin{array}{l}\text { Overall cancer } \\
(\mathrm{n}=5,269)\end{array}$ & $\begin{array}{l}\text { Gastric cancer } \\
\quad(\mathrm{n}=731)\end{array}$ & $\begin{array}{l}\text { Colon cancer } \\
(\mathrm{n}=378)\end{array}$ & $\begin{array}{l}\text { Breast cancer } \\
\quad(\mathrm{n}=875)\end{array}$ & $\begin{array}{l}\text { Cervical cancer } \\
\quad(\mathrm{n}=609)\end{array}$ & $\begin{array}{l}\text { Thyroid cancer } \\
\qquad(\mathrm{n}=888)\end{array}$ \\
\hline $\begin{array}{l}\text { Total calories } \\
\text { (kcal) }\end{array}$ & $1,739.1 \pm 576.2$ & $1,699.2 \pm 559.4^{a}$ & $1,681.3 \pm$ & 1 & $1,662.1 \pm 55.85^{b}$ & $1,661.5 \pm 541.4$ & $2,734.4 \pm 587.4$ \\
\hline $\begin{array}{l}\text { Cereals and } \\
\text { grain (\%) }\end{array}$ & $34.37 \pm 16.43$ & $33.51 \pm 16.12^{\mathrm{a}}$ & $34.80 \pm 16.25$ & $34.27 \pm 16.94$ & $31.60 \pm 15.17^{\mathrm{b}}$ & $34.07 \pm 16.88$ & $34.07 \pm 15.32$ \\
\hline $\begin{array}{l}\text { Potatoes and } \\
\text { starches (\%) }\end{array}$ & $3.17 \pm 2.49$ & $3.50 \pm 2.97^{\mathrm{a}}$ & $3.70 \pm 3.04^{b}$ & $3.47 \pm 2.65$ & $3.63 \pm 3.00^{b}$ & $3.55 \pm 3.22$ & $3.55 \pm 2.65$ \\
\hline $\begin{array}{l}\text { Sugars and } \\
\text { sweets (\%) }\end{array}$ & $1.58 \pm 1.46$ & $1.43 \pm 1.51^{\mathrm{a}}$ & $1.86 \pm 2.06^{\mathrm{b}}$ & $1.40 \pm 1.44$ & $1.18 \pm 1.30^{\mathrm{b}}$ & $1.47 \pm 1.38$ & $1.47 \pm 1.34^{\mathrm{b}}$ \\
\hline Legume (\%) & $4.18 \pm 3.29$ & $4.56 \pm 3.52^{\mathrm{a}}$ & $4.59 \pm 3.41$ & $4.71 \pm 3.35$ & $4.71 \pm 3.76^{b}$ & $4.42 \pm 3.42$ & $4.42 \pm 3.26$ \\
\hline $\begin{array}{l}\text { Seeds and nuts } \\
(\%)\end{array}$ & $0.85 \pm 1.50$ & $1.13 \pm 1.91^{\mathrm{a}}$ & $1.16 \pm 1.83^{\mathrm{b}}$ & $1.05 \pm 1.56$ & $1.30 \pm 1.99^{\mathrm{b}}$ & $0.92 \pm 1.57$ & $0.92 \pm 1.96^{\mathrm{b}}$ \\
\hline Vegetables (\%) & $6.79 \pm 3.55$ & $7.00 \pm 3.54^{\mathrm{a}}$ & $7.11 \pm 3.54$ & $7.18 \pm 3.55$ & $7.11 \pm 3.46$ & $6.89 \pm 3.48$ & $6.89 \pm 3.13$ \\
\hline Mushrooms (\%) & $0.31 \pm 0.33$ & $0.32 \pm 0.34^{\mathrm{a}}$ & $0.35 \pm 0.41$ & $0.30 \pm 0.30$ & $0.32 \pm 0.33$ & $0.30 \pm 0.34$ & $0.30 \pm 0.30$ \\
\hline Fruits (\%) & $18.50 \pm 12.71$ & $20.29 \pm 12.94^{\mathrm{a}}$ & $19.48 \pm 12.76$ & $19.82 \pm 12.84$ & $22.59 \pm 12.81$ & $19.66 \pm 12.82$ & $19.66 \pm 12.98$ \\
\hline $\begin{array}{l}\text { Meat and } \\
\text { poultry (\%) }\end{array}$ & $9.77 \pm 7.58$ & $7.82 \pm 6.79^{\mathrm{a}}$ & $8.25 \pm 7.44^{b}$ & $7.75 \pm 6.84^{b}$ & $6.35 \pm 6.28^{\mathrm{b}}$ & $7.66 \pm 6.46^{\mathrm{b}}$ & $7.66 \pm 6.56^{\mathrm{b}}$ \\
\hline Eggs (\%) & $1.45 \pm 1.57$ & $1.48 \pm 1.63$ & $1.56 \pm 1.70$ & $1.41 \pm 1.56$ & $1.51 \pm 1.72$ & $1.45 \pm 1.60$ & $1.45 \pm 1.62$ \\
\hline $\begin{array}{l}\text { Fishes and } \\
\text { shellfishes (\%) }\end{array}$ & $4.98 \pm 3.44$ & $5.00 \pm 3.39$ & $4.93 \pm 3.32$ & $4.95 \pm 3.15$ & $4.99 \pm 3.31$ & $5.10 \pm 3.51$ & $5.10 \pm 3.45$ \\
\hline Seaweeds (\%) & $0.15 \pm 0.13$ & $0.16 \pm 0.14$ & $0.16 \pm 0.15$ & $0.16 \pm 0.13$ & $0.16 \pm 0.13$ & $0.16 \pm 0.17$ & $0.16 \pm 0.12$ \\
\hline $\begin{array}{l}\text { Milks and } \\
\text { dairy (\%) }\end{array}$ & $6.41 \pm 6.33$ & $6.26 \pm 6.33$ & $4.59 \pm 5.83^{b}$ & $5.96 \pm 6.31$ & $6.79 \pm 6.37$ & $6.79 \pm 6.20$ & $6.79 \pm 6.38$ \\
\hline Oils and fats (\%) & $1.95 \pm 1.57$ & $1.71 \pm 1.48^{\mathrm{a}}$ & $2.01 \pm 1.68$ & $1.78 \pm 1.56$ & $1.45 \pm 1.30^{\mathrm{b}}$ & $1.74 \pm 1.44$ & $1.74 \pm 1.43^{\mathrm{b}}$ \\
\hline Beverage (\%) & $3.14 \pm 4.28$ & $3.20 \pm 4.58$ & $2.78 \pm 3.86$ & $2.95 \pm 3.93$ & $3.53 \pm 5.32$ & $3.22 \pm 4.44$ & $3.22 \pm 4.23$ \\
\hline Seasonings (\%) & $2.38 \pm 1.38$ & $2.61 \pm 1.54^{\mathrm{a}}$ & $2.65 \pm 1.54^{\mathrm{b}}$ & $2.82 \pm 1.74^{\mathrm{b}}$ & $2.76 \pm 1.63^{b}$ & $2.57 \pm 1.57$ & $2.57 \pm 1.32$ \\
\hline Others (\%) & $0.01 \pm 0.05$ & $0.02 \pm 0.06^{\mathrm{a}}$ & $0.01 \pm 0.04$ & $0.02 \pm 0.06$ & $0.02 \pm 0.06$ & $0.01 \pm 0.05$ & $0.01 \pm 0.07^{\mathrm{b}}$ \\
\hline
\end{tabular}

Values are presented as mean $\pm \mathrm{SD} .{ }^{\mathrm{a}} P<0.05$ compared with healthy population in a two-independent samples $t$-test. ${ }^{\mathrm{b}} P<0.01$ (Bonferroni adjustment) compared with healthy population in a multiple comparison Tukey test. 
measured as the proportion of nutrition intake from 17 types of food groups between all cancers and each cancer type of survivors and matched healthy population, (OR and 95\% CIs were calculated by using logistic regression (all cancer survivors versus healthy population) and polychotomous logistic regression (each type of cancer survivors such as gastric, colon, breast, cervical, and thyroid cancer survivors versus healthy population) adjusted for baseline characteristic variables including age, sex, marital status, education, income, employment, smoking, drinking, regular exercise, body mass index, and total calorie intake.

\section{RESULTS}

Table 1 shows the baseline sociodemographic characteristics of 5,269 cancer survivors and 5,219 matched healthy people from the HEXA cohort. Age and sex, which were considered in matching process, were equally distributed in cancer survivors and healthy population group. Employment status, smoking, drinking, and physical activity were significantly different between cancer survivors and matched healthy population $(P<$ 0.001). Further, cancer survivors reported a greater likelihood of unemployment, a former history of smoking and drinking, a regularity of physical exercise, and being obese, but less likely to be a current drinker.

The mean proportion of calories intake from 17 food groups in cancer survivors and matched healthy population was compared in Table 2. Overall, the proportion of calories intake from potatoes and starches, legume, seeds and nuts, vegetables, mushrooms, fruits, and seasonings in cancer survivors were higher than healthy people $(P<0.05)$. In contrast, cereals and grain, sugars and sweets, meat and poultry, and oils and fats accounted for the lower proportion in cancer survivors' calories intake than in those of healthy population $(P<0.05)$. In the subgroup analysis by types of cancer, most of the results appeared to be similar with overall cancer. For examples, the proportion of calories from seeds and nuts tended to be higher in gastric cancer, breast cancer, and thyroid cancer survivors than healthy population $(P<0.01)$. Calories from seasonings were observed to much more intake in gastric cancer, colon cancer, and breast cancer patients $(P<0.01)$. Also, there was a significant lower consume of meat and poultry in all five types of cancer $(P<0.01)$.

The differences of calories intake proportion from each 17 food groups which was divided by median level of the proportion of each good group between cancer survivors and healthy

Table 3. OR and $95 \%$ CIs for calories intake proportion above the median value in cancer survivors compared with healthy population

\begin{tabular}{|c|c|c|c|c|c|c|}
\hline & $\begin{array}{l}\text { Overall cancer }^{\mathrm{a}, \mathrm{c}} \\
\quad(\mathrm{n}=5,269)\end{array}$ & $\begin{array}{l}\text { Gastric cancer }{ }^{\mathrm{a}, \mathrm{d}} \\
\qquad(\mathrm{n}=731)\end{array}$ & $\begin{array}{l}\text { Colon } \text { cancer }^{\mathrm{a}, \mathrm{d}} \\
\quad(\mathrm{n}=378)\end{array}$ & $\begin{array}{l}\text { Breast cancer }{ }^{\mathrm{a}, \mathrm{d}} \\
\quad(\mathrm{n}=875)\end{array}$ & $\begin{array}{l}\text { Cervical cancer }{ }^{\mathrm{a}, \mathrm{d}} \\
\qquad(\mathrm{n}=609)\end{array}$ & $\begin{array}{l}\text { Thyroid cancer }{ }^{\mathrm{a}, \mathrm{d}} \\
\quad(\mathrm{n}=888)\end{array}$ \\
\hline $\begin{array}{l}\text { Cereals and } \\
\text { grain }\end{array}$ & $1.01 \quad(0.95-1.07)$ & $1.03(0.92-1.16)$ & $0.97(0.84-1.13)$ & $0.95(0.86-1.06)$ & $0.97(0.86-1.09)$ & $1.02(0.92-1.13)$ \\
\hline $\begin{array}{l}\text { Potatoes and } \\
\text { starches }\end{array}$ & $1.09(1.03-1.16)^{b}$ & $1.27(1.13-1.43)^{\mathrm{b}}$ & $1.17(1.00-1.36)^{\mathrm{b}}$ & $1.08(0.97-1.20)$ & $1.02(0.91-1.16)$ & $1.05(0.94-1.16)$ \\
\hline $\begin{array}{l}\text { Sugars and } \\
\text { sweets }\end{array}$ & $0.83(0.79-0.88)^{b}$ & $1.04(0.92-1.17)$ & $0.75(0.65-0.88)^{b}$ & $0.74(0.66-0.82)^{b}$ & $0.90(0.80-1.02)$ & $0.81(0.73-0.90)^{b}$ \\
\hline Legume & $1.13(1.06-1.19)^{b}$ & $1.18(1.05-1.32)^{b}$ & $1.2(1.03-1.39)^{b}$ & $1.14(1.03-1.27)^{b}$ & $1.17(1.03-1.32)^{\mathrm{b}}$ & $1.02(0.92-1.13)$ \\
\hline Seeds and nuts & $1.15(1.09-1.22)^{b}$ & $1.29(1.15-1.45)^{\mathrm{b}}$ & $1.08(0.93-1.26)$ & $1.31(1.18-1.46)^{b}$ & $1.01(0.90-1.15)$ & $1.16(1.05-1.29)^{b}$ \\
\hline Vegetables & $1.07(1.01-1.13)^{b}$ & $1.14(1.02-1.28)^{\mathrm{b}}$ & $1.18(1.01-1.37)^{\mathrm{b}}$ & $1.11(1.00-1.23)^{b}$ & $1.03(0.91-1.16)$ & $0.95(0.86-1.06)$ \\
\hline Mushrooms & $1.07(1.02-1.14)^{b}$ & $1.09(0.97-1.23)$ & $0.99(0.85-1.15)$ & $1.13(1.01-1.25)^{\mathrm{b}}$ & $1.02(0.91-1.16)$ & $1.13(1.02-1.25)^{\mathrm{b}}$ \\
\hline Fruits & $1.15(1.08-1.21)^{b}$ & $1.15(1.02-1.29)^{\mathrm{b}}$ & $1.25(1.07-1.46)^{b}$ & $1.31(1.18-1.46)^{b}$ & $1.04(0.92-1.18)$ & $1.19(1.07-1.32)^{\mathrm{b}}$ \\
\hline $\begin{array}{l}\text { Meat and } \\
\text { poultry }\end{array}$ & $0.75(0.71-0.80)^{b}$ & $0.73(0.65-0.83)^{b}$ & $0.71(0.61-0.83)^{b}$ & $0.59(0.53-0.66)^{b}$ & $0.79(0.69-0.89)^{\mathrm{b}}$ & $0.86(0.77-0.95)^{b}$ \\
\hline Eggs & $1.02(0.96-1.08)$ & $1.11(0.99-1.25)$ & $1.04(0.89-1.21)$ & $1.01(0.91-1.12)$ & $0.96(0.85-1.09)$ & $1.03(0.93-1.14)$ \\
\hline $\begin{array}{l}\text { Fishes and } \\
\text { shellfishes }\end{array}$ & $0.99(0.93-1.04)$ & $0.96(0.86-1.08)$ & $0.98(0.84-1.14)$ & $1.02(0.92-1.14)$ & $1.03(0.92-1.17)$ & $0.95(0.86-1.05)$ \\
\hline Seaweeds & $0.99(0.94-1.05)$ & $1.04(0.93-1.17)$ & $1.08(0.92-1.25)$ & $1.01(0.91-1.13)$ & $1.00(0.88-1.13)$ & $0.86(0.78-0.96)^{b}$ \\
\hline Milks and dairy & $0.97(0.91-1.02)$ & $0.67(0.59-0.75)^{\mathrm{b}}$ & $0.99(0.85-1.15)$ & $0.97(0.87-1.08)$ & $1.09(0.97-1.23)$ & $1.06(0.96-1.18)$ \\
\hline Oils and fats & $0.84(0.80-0.89)^{b}$ & $0.98(0.87-1.10)$ & $0.86(0.73-1.00)^{b}$ & $0.75(0.67-0.83)^{b}$ & $0.91 \quad(0.80-1.03)$ & $0.79(0.71-0.88)^{b}$ \\
\hline Beverage & $0.93(0.88-0.99)^{b}$ & $0.86(0.76-0.96)^{b}$ & $0.94(0.81-1.09)$ & $0.96(0.86-1.06)$ & $0.98(0.87-1.11)$ & $0.98(0.88-1.08)$ \\
\hline Seasonings & $1.17(1.10-1.23)^{b}$ & $1.34(1.19-1.50)^{b}$ & $1.27(1.09-1.48)^{\mathrm{b}}$ & $1.20(1.08-1.34)^{b}$ & $1.11(0.98-1.25)$ & $1.10(0.99-1.22)$ \\
\hline Others & $1.07(1.01-1.15)^{b}$ & $0.88(0.76-1.01)$ & $1.01 \quad(0.85-1.20)$ & $1.20(1.07-1.35)^{b}$ & $1.07(0.94-1.23)$ & $1.18(1.05-1.32)^{\mathrm{b}}$ \\
\hline
\end{tabular}

${ }^{a}$ Adjusted for total calories intake, marital status, education, income, employment, smoking, drinking, regular exercise, body mass index, and total calorie intake. ${ }^{\mathrm{b}} p<0.05$ for significant level of overall cancer survivors compared with healthy population. ${ }^{\mathrm{C}}$ Result from logistic regression. ${ }^{\mathrm{d}}$ Result from polychotomous logistic regression. 
population after adjusted for other possible covariates and total calorie intake were provided in Table 3 as ORs an 95\% CIs. Compared with healthy population, cancer survivors' intake of each food group above median value was higher in the aspect of the proportion of calories intake from potatoes and starches, legume and their products, seeds and nuts, vegetables, mushrooms, fruits, and seasonings with OR (95\% CI) of 1.09 (1.03-1.16), 1.13 (1.06-1.19), 1.15 (1.09-1.22), 1.07 (1.01-1.13), 1.07 (1.02-1.14), 1.15 (1.08-1.21), and 1.17 (1.10-1.23), respectively. However, the more cancer survivors showed intake of less than median value of calories intakes from sugars and sweets, meat and poultry, oils and fats, and beverage were obtained in cancer survivors with OR ( $95 \% \mathrm{CI}$ ) of 0.83 (0.79-0.88), 0.75 (0.71-0.80), $0.84(0.80-0.89)$, and $0.93(0.88-0.99)$. When we conducted the subgroup analysis for five main types of cancer individuals, the higher intake patterns above the median value were more prominently observed in breast, colon, and thyroid cancer survivors compared to healthy people and lower intake patterns below the median value were consistently observed in gastric and breast cancer survivors.

\section{DISCUSSION}

With the growing number of cancer incidences as well as the development of diagnostic and therapeutic techniques, increased number of cancer survivors in worldwide would be inevitable [19]. Modifiable lifestyle factors, especially nutritional status plays as an important predictor of quality of life in cancer survivors [20]. This study aimed to investigate and compare the food intake behavior between cancer survivors and healthy population in an East Asian country. The results from both ANOVA and logistic regression suggested the higher proportion of calories intake above the median value from potatoes and starches, legume, seeds and nuts, vegetables, mushrooms, fruits, and seasonings and the less proportion of calories intake below the median value of sugars and sweets, meat and poultry, oils and fats, and beverage in cancer survivors, in comparison with healthy subjects. These significantly higher proportion above the median value were mostly observed in breast, colon, and thyroid cancer survivors and less proportion of calories intake below the median value were observed in gastric and breast cancer survivors.

In general, fruits and vegetables, which are high in the amount of antioxidants, dietary fiber, as well as phytoestrogens, have the protective effect on different types of cancer [21-25]. On the other hand, salty food and red meat, which contain pro-inflammatory fatty acids or nitrate and nitrite, are associated with an increased risk of chronic disease and cancer [21,25,26]. Dietary factors in terms of food item and cancer risk have been mentioned in the cancer prevention recommendations of World Cancer Research Fund/American Institute for Cancer Research (WCRF/AICR) and the American Cancer Society (ACS) [21,25]. Adherence to WCRF/AICR guideline was also associated with an improvement of health-related quality of life and lower mortality among cancer survivors $[27,28]$. Cancer survivors who follow ACS recommendation of fruit and vegetable consumption also showed a better health-related quality of life [29]. The result from the current study indicated that the cancer survivors in an East Asian country performed the high level of adherence to these guidelines. It can be explained that cancer survivors much more focused on healthy lifestyle behaviors after diagnosis with cancer, especially on diet patterns [30,31]. Despite the adherence to the guidelines, several studies conducting on Asian population showed the low level of calories or fatty acid intake in both cancer survivors and general population, compared with population from Western countries [32,33]. Although high fat diet is not recommended for cancer survivors, cancer survivors are suggested to consume much more specific types of oil, such as olive oil and fish oil as well as the higher amount of total calories from these fat because they are the enriched diet of polyunsaturated omega-3 fatty acids and monounsaturated fatty acids which have been reported to have beneficial effects of reducing chronic disease and cancer risk [34-36]. However, in this study, differences in fish intake was not observed between cancer survivors and healthy population.

Inconsistent results were found in previous studies regarding whether cancer survivors performed the inadequate adherence of healthy diet in Western population [12]. General population in Western countries originally follows the Western diet, which characterized by high intake of saturated fats, animal-protein and low intake of plant-based meal [37]. The differences of food intake behaviors in cancer survivors may result from both the background food intake behaviors in general population and the changes in eating behaviors after cancer diagnosis and treatment. Although cancer survivors would be more aware of dietary role in cancer risk, it was found that they had not received enough professional dietary advice as well as were unsure about other sources of information that they got advice about their diet intake [38]. Cancer survivors should be well-received such kinds of dietary guidance from health professionals as well as clear recommendations on behavior eating, which emphasize the benefits and importance of healthy diet [38].

To the best of the authors' knowledge, this is one of the few studies which investigated the difference in food intake behavior 
between cancer survivors and healthy population, especially in East Asian countries. Based on a baseline data from a large, representative cohort study in Korea, survivors of five major cancers including gastric, colon, breast, cervical, and thyroid cancer [39] were compared with non-cancer subjects. Additionally, the daily calories intake was calculated by a specific nutrition software and update version CAN-Pro 4.0, which is developed for Korean population based on food culture of Korea. In addition, to increase comparability between cancer survivors and healthy population, we matched age and sex, in addition to adjustment for other baseline socio-demographic variables in the analysis. Some limitations of this study should be mentioned. First, the identification of cancer survivors and healthy population was based on self-reported questionnaire, which might lead to misclassification. However, a recent report regarding validity of self-reported cancer history in the HEXA cohort showed good accuracy [4], proposing limited misclassification. Second, although FFQ have been commonly used to access dietary intake, the measurement errors such as variations in the portion size or limited correlation with other dietary measurement tools, especially in Asian countries, should be considered when the results are interpreted. However, it would be a nondifferential misclassification, thus the impact to the results would be minimal. We did not consider years since cancer diagnosis in cancer survivors when the dietary pattern assessed due to multiple comparison issues, followed by limited sample size for cancer type. Considering that health behaviors are affected by time since diagnosis, our assessment would not reflect diet pattern affected by time. Finally, this is a health examinationbased study, which has the lower power of generalization than population-based study. Patients enrolled in this study might be healthier than general cancer patients and healthy population tended to concern more about their dietary lifestyle. However, the comparability between cancer survivors and controls would be a strength because the study population came from the same cohort.

The dietary behavior measured by main sources of energy intake in overall cancer survivors as well as main types of cancer is different from healthy individuals in terms of several food groups. We observed the positive behavior of dietary intake among cancer survivors, with the higher intake of potatoes and starches, legume, seeds and nuts, vegetables, mushrooms, fruits, and seasonings and the less intake of sugars and sweets, meat and poultry, oils and fats, and beverage in cancer survivors, in comparison with healthy subjects. These patterns indicated the high adherence of East Asian population to healthy guidelines for cancer survivors. However, due to the differences of food culture between Western population and Asian people, such the nutritional guidelines for cancer survivors in Asia need to be more considered. Therefore, the guideline of balanced nutritious behavior should be established among Asian cancer survivors.

\section{ACKNOWLEDGMENTS}

This work was supported by the Basic Science Research Program through the National Research Foundation of Korea (NRF) funded by the Ministry of Science, ICT and Future Planning (NRF-2019R1H1A1079862) and a research grant in 2019 by the Korean Foundation for Cancer Research, Seoul, Republic of Korea. This study used data from the Korean Genome Analysis Project (4845-301), the Korean Genome and Epidemiology Study (4851302), and the Korea Biobank Project (4851-307, KBP-2014-041), which were supported by the Korea Centers for Disease Control and Prevention, Republic of Korea.

\section{CONFLICTS OF INTEREST}

No potential conflicts of interest were disclosed.

\section{ORCID}

\author{
Tung Hoang, \\ https://orcid.org/0000-0001-6653-3406 \\ Jeonghee Lee, \\ https://orcid.org/0000-0001-9072-6507 \\ Jeongseon Kim, \\ https://orcid.org/0000-0002-0889-2686 \\ Boyoung Park, \\ https://orcid.org/0000-0003-1902-3184
}

\section{REFERENCES}

1. Global Burden of Disease Cancer Collaboration, Fitzmaurice C, Allen C, Barber RM, Barregard L, Bhutta ZA, et al. Global, regional, and national cancer incidence, mortality, years of life lost, years lived with disability, and disability-adjusted life-years for 32 cancer groups, 1990 to 2015: a systematic analysis for the Global Burden of Disease study. JAMA Oncol 2017:3:524-48.

2. Rowland JH, Kent EE, Forsythe LP, Loge JH, Hjorth L, Glaser A, et al. Cancer survivorship research in Europe and the United States: where have we been, where are we going, and what can we learn from each other? Cancer 2013;119 Suppl 11:2094-108.

3. IARC. GLOBOCAN 2012: estimated cancer incidence, mortality, and prevalence worldwide in 2012. Lyon, IARC, 2014. 
4. Cho S, Shin A, Song D, Park JK, Kim Y, Choi JY, et al. Validity of self-reported cancer history in the health examinees (HEXA) study: a comparison of self-report and cancer registry records. Cancer Epidemiol 2017;50(Pt A):16-21.

5. Jung KW, Won YJ, Park S, Kong HJ, Sung J, Shin HR, et al. Cancer statistics in Korea: incidence, mortality and survival in 2005. J Korean Med Sci 2009:24:995-1003.

6. Gallicchio L, Kalesan B, Hoffman SC, Helzlsouer KJ. Non-cancer adverse health conditions and perceived health and function among cancer survivors participating in a community-based cohort study in Washington County, Maryland. J Cancer Surviv 2008;2:12-9.

7. Eakin EG, Youlden DR, Baade PD, Lawler SP, Reeves MM, Heyworth JS, et al. Health behaviors of cancer survivors: data from an Australian population-based survey. Cancer Causes Control 2007; 18:881-94.

8. Bamia C. Dietary patterns in association to cancer incidence and survival: concept, current evidence, and suggestions for future research. Eur J Clin Nutr 2018;72:818-25.

9. Woo HD, Park S, Oh K, Kim HJ, Shin HR, Moon HK, et al. Diet and cancer risk in the Korean population: a meta-analysis. Asian Pac J Cancer Prev 2014:15:8509-19.

10. Schwedhelm C, Boeing H, Hoffmann G, Aleksandrova K, Schwingshackl L. Effect of diet on mortality and cancer recurrence among cancer survivors: a systematic review and meta-analysis of cohort studies. Nutr Rev 2016;74:737-48.

11. Park B, Lee J, Kim J. Imbalanced nutrient intake in cancer survivors from the examination from the nationwide health examination center-based cohort. Nutrients 2018;10:E212.

12. Zhang FF, Liu S, John EM, Must A, Demark-Wahnefried W. Diet quality of cancer survivors and noncancer individuals: results from a national survey. Cancer 2015;121:4212-21.

13. Scarborough P, Nnoaham KE, Clarke D, Capewell S, Rayner M. Modelling the impact of a healthy diet on cardiovascular disease and cancer mortality. J Epidemiol Community Health 2012;66:420-6.

14. Kim Y, Han BG; KoGES group. Cohort profile: The Korean Genome and Epidemiology Study (KoGES) consortium. Int J Epidemiol 2017:46:1350.

15. Health Examinees Study Group. The Health Examinees (HEXA) study: rationale, study design and baseline characteristics. Asian Pac J Cancer Prev 2015;16:1591-7.

16. DeSantis CE, Lin CC, Mariotto AB, Siegel RL, Stein KD, Kramer JL, et al. Cancer treatment and survivorship statistics, 2014. CA Cancer J Clin 2014:64:252-71.

17. Ahn Y, Kwon E, Shim JE, Park MK, Joo Y, Kimm K, et al. Validation and reproducibility of food frequency questionnaire for Korean genome epidemiologic study. Eur J Clin Nutr 2007;61:1435-41.

18. The Korean Nutrition Society. Computer aided nutritional analysis program for professionals. Seoul, The Korean Nutrition Society, 2010.

19. Corkum M, Hayden JA, Kephart G, Urquhart R, Schlievert C, Porter G. Screening for new primary cancers in cancer survivors compared to non-cancer controls: a systematic review and meta-analysis. J Cancer Surviv 2013;7:455-63.

20. Lis CG, Gupta D, Lammersfeld CA, Markman M, Vashi PG. Role of nutritional status in predicting quality of life outcomes in cancer--a systematic review of the epidemiological literature. Nutr J 2012;11:27.
21. American Institute for Cancer Research. Food, nutrition, physical activity, and the prevention of cancer: a global perspective. Washington, DC, AICR, 2007.

22. Wang X, Ouyang Y, Liu J, Zhu M, Zhao G, Bao W, et al. Fruit and vegetable consumption and mortality from all causes, cardiovascular disease, and cancer: systematic review and dose-response meta-analysis of prospective cohort studies. BMJ 2014:349:84490.

23. Turati F, Rossi M, Pelucchi C, Levi F, La Vecchia C. Fruit and vegetables and cancer risk: a review of southern European studies. Br J Nutr 2015;113 Suppl 2:S102-10.

24. Aune D, Chan DS, Lau R, Vieira R, Greenwood DC, Kampman E, et al. Dietary fibre, whole grains, and risk of colorectal cancer: systematic review and dose-response meta-analysis of prospective studies. BMJ 2011;343:d6617.

25. Rock CL, Doyle C, Demark-Wahnefried W, Meyerhardt J, Courneya KS, Schwartz AL, et al. Nutrition and physical activity guidelines for cancer survivors. CA Cancer J Clin 2012;62: 243-74.

26. Okręglicka K. Health effects of changes in the structure of dietary macronutrients intake in western societies. Rocz Panstw Zakl Hig 2015;66:97-105.

27. Inoue-Choi M, Robien $\mathrm{K}$, Lazovich $\mathrm{D}$. Adherence to the WCRF/ ICR guidelines for cancer prevention is associated with lower mortality among older female cancer survivors. Cancer Epidemiol Biomarkers Prev 2013;22:792-802.

28. Inoue-Choi M, Lazovich D, Prizment AE, Robien K. Adherence to the World Cancer Research Fund/American Institute for Cancer Research recommendations for cancer prevention is associated with better health-related quality of life among elderly female cancer survivors. J Clin Oncol 2013;31:1758-66.

29. Blanchard CM, Courneya KS, Stein K; American Cancer Society's SCS-II. Cancer survivors' adherence to lifestyle behavior recommendations and associations with health-related quality of life: results from the American Cancer Society's SCS-II. J Clin Oncol 2008;26:2198-204.

30. Stull VB, Snyder DC, Demark-Wahnefried W. Lifestyle interventions in cancer survivors: designing programs that meet the needs of this vulnerable and growing population. J Nutr 2007; 37(1 Suppl):243S-8S.

31. Nayir E, Bakir Koyuncu M, Esin E, Turker I, Tanriverdi O, Uysal $\mathrm{M}$, et al. Attitudes of cancer patients after diagnosis: how cancer affects social life? A Turkish Oncology Group study. J BUON 2017;22:208-13.

32. Harika RK, Eilander A, Alssema M, Osendarp SJ, Zock PL. Intake of fatty acids in general populations worldwide does not meet dietary recommendations to prevent coronary heart disease: a systematic review of data from 40 countries. Ann Nutr Metab 2013;63:229-38.

33. Mohammadi S, Sulaiman S, Koon PB, Amani R, Hosseini SM. Association of nutritional status with quality of life in breast cancer survivors. Asian Pac J Cancer Prev 2013; 14:7749-55.

34. Serhan CN. Novel lipid mediators and resolution mechanisms in acute inflammation: to resolve or not? Am J Pathol 2010;177: 576-91.

35. Ramsden CE, Faurot KR, Carrera-Bastos P, Cordain L, De Lorgeril M, Sperling LS. Dietary fat quality and coronary heart disease prevention: a unified theory based on evolutionary, historical, global, and modern perspectives. Curr Treat Options Cardiovasc 
Med 2009;11:289-301.

36. Gao M, Sun K, Guo M, Gao H, Liu K, Yang C, et al. Fish consumption and n-3 polyunsaturated fatty acids, and risk of hepatocellular carcinoma: systematic review and meta-analysis. Cancer Causes Control 2015;26:367-76.

37. Pistollato F, Sumalla Cano S, Elio I, Masias Vergara M, Giampieri F, Battino M. Associations between sleep, cortisol regulation, and diet: possible implications for the risk of Alzheimer disease.
Adv Nutr 2016;7:679-89.

38. Beeken RJ, Williams K, Wardle J, Croker H. "What about diet?" A qualitative study of cancer survivors' views on diet and cancer and their sources of information. Eur J Cancer Care (Engl) 2016;25:774-83.

39. Jung KW, Won YJ, Oh CM, Kong HJ, Lee DH, Lee KH. Prediction of cancer incidence and mortality in Korea, 2017. Cancer Res Treat 2017:49:306-12. 